\title{
HER2/neu Oncogene and Sensitivity to the DNA-Interactive Drug Doxorubicin
}

\author{
Anne Elizabeth Mullin*† and Bertrand Jean-Claude, Ph.D. ${ }^{\dagger}$
}

\begin{abstract}
Breast tumor cells overexpressing the proto-oncogene HER2/neu are known to be less responsive to certain DNA-binding chemotherapeutic agents. The current study specifically investigates the correlation between chemosensitivity to the DNA-binding drug doxorubicin and cellular HER2/neu protein levels in a panel of eight breast cancer cell lines (HS-578, BT-474, MDA-MB-453, MDA-MB-231, MDA-MB-175, MCF-7, ZR-75-1 and T47D). The $\mathrm{IC}_{50}$ (the drug concentration required to inhibit cell growth by $50 \%$ ) values for the cell lines were determined by the sulforhodamine $B$ assay. IC $_{50}$ values were correlated with HER2/neu protein levels determined by Western blotting. An almost linear relationship between $\mathrm{IC}_{50}$ and HER2/neu protein level for seven cell lines $\left(p=0.02, r^{2}=0.680\right)$ was found, with protein levels increasing as resistance increased. The findings suggest that overexpression of HER2/neu correlates with increased resistance to doxorubicin in seven of eight breast cancer cell lines studied. The observation that, in one cell line (MDA-MB-175), doxorubicin $\mathrm{IC}_{50}$ did not correlate with HER2/neu levels, suggests that in these cells, an as-of-yet unidentified factor contributes to resistance. If the observed correlation, which was present in seven of eight cell lines, is confirmed in a larger sample size, increased HER2/neu levels may be implemented as a predictor of breast tumor sensitivity to doxorubicin.
\end{abstract}

\section{INTRODUCTION}

Breast tumors are characterized by a variety of cellular disorders, including mutations and overexpression of signal transduction proteins. Notably, the mutation and overexpression of the proto-oncogene HER2/neu has been observed in 15 to $35 \%$ of breast tumors (1-6). Many other malignancies, including ovarian, gastric and kidney tumors have also exhibited overexpression of the HER2/neu protein $(1,7,8)$. These observations have generated attempts to use antiHER2/neu antibodies to specifically deliver chemotheraupeutic drugs to tumors (9).

The HER2/neu (c-erbB-2) proto-oncogene is located on chromosome $17 \mathrm{q} 21$ and encodes a $185 \mathrm{kD}$

\footnotetext{
* To whom correspondence should be addressed.

$\dagger$ Department of Oncology, McGill University, McIntyre Medical Sciences Building, 3655 Drummond St., Montreal, Quebec, Canada H3G 1 Y6
}

transmembrane phosphoglycoprotein, which consists of an intracellular kinase and a cysteine-rich extracellular receptor domain (10). HER2/neu belongs to a family of proteins, which, like the epidermal growth factor receptor, regulate cell growth as receptor tyrosine kinases (11-13).

The oncogenic potential of the HER2/neu protein can emerge in two ways. First, the proto-oncogene may be altered by a single point mutation that replaces valine 664 with a glutamic acid residue $(12,14)$. A structurally altered gene product is generated that confers transforming potential, enhanced tyrosine kinase activity and ultimately enhanced cell proliferation (12). Second, gene transfer experiments have demonstrated that amplification of the normal HER2/neu gene product alone is sufficient to induce cell transformation and oncogenic potential (15), while antisense oligonucleotides specific for HER2/neu cause a reduction in cell growth (16). 
The mechanism of enhanced proliferation is believed to be increased ligand-induced receptorreceptor interactions or overthreshold ligand-induced stimulation in cells overexpressing HER2/neu $(12,17,18)$. Additionally, poor patient prognosis and aggressive tumor growth are associated with overexpression of HER2/neu in several tumor types $(2,19-21)$. Further, studies have suggested that this oncogene may be involved in tumor resistance to chemotherapeutic drugs (20-22).

In the past 20 years, many antineoplastic agents have been isolated and synthesized. Of these, doxorubicin (DOX; Adriamycin) has emerged as the most utilized antitumor drug worldwide $(23,24)$. Clinically, this anthracycline is used to treat many solid tumors, such as carcinomas of the breast, bladder, endometrium, lung, ovaries, stomach and thyroid, as well as sarcomas of bone and soft tissue, pediatric solid tumors and lymphoid tumors (24).

The cytotoxicity of DOX is mediated via its capacity to covalently bind double stranded DNA. This subsequently induces protein-linked double strand DNA breaks through the action of topoisomerase II $\alpha$ (24). Topoisomerase II $\alpha$ controls DNA supercoiling by cleaving and reannealing double stranded DNA. Intercalators such as DOX interfere with topoisomerase II by stabilizing the cleavable complex, which converts the enzyme into a cellular poison (25-27). The importance of topoisomerase II in the antineoplastic mechanism of DOX has been highlighted by studies demonstrating that decreases in topoisomerase II expression leads to resistance to DOX $(28,29)$.

Other mechanisms of anthracyclines include inhibition of DNA synthesis and RNA polymerases, and formation of free radicals $(24,30)$. Further, free radical formation has also been implicated as a mechanism by which DOX kills human breast cancer cell line MCF-7 in vitro $(31,32)$.

Unfortunately, the use of DOX in cancer chemotherapy is frequently plagued by tumor resistance, which, in some cases, is mediated by the human multidrug resistance-associated protein Pgp $(33,34)$. However, not all resistance can be explained by this mechanism. As previously mentioned, HER2/neu has also been implicated in DOX resistance (20-22). Evidence, such as increased sensitivity to DOX and other antineoplastic agents following reduction in HER2/neu activity by treatment with antiHER2/neu antibody $(35,36)$ and antisense oligonucleotides (37) and resistance to DOX correlating with HER2/neu expression in cancer cells lines $(23,24,38,39)$, suggest that HER2/neu is related to DOX resistance. Furthermore, there is preliminary evidence that drug resistance linked to overexpression of the HER2/nеu is a consequence of its role in DNA repair $(40,41)$.

However, the relevant studies do not entirely agree with the hypothesis that HER2/neu expression correlates with chemoresistance. Namely, Pedram et al. demonstrated that HER2/neu overexpression was not sufficient to produce drug resistance in breast and ovarian cancer cell lines (42). Also, basic evidence suggests that increased HER2/neu activation leads to increases in topoisomerase II expression (43) and reduced gene copies of HER2/neu are linked to decreased gene copies of topoisomerase II (44). These studies suggest that increased HER2/neu would lead to increased topoisomerase II $\alpha$, which would increase the antineoplastic activity of DOX. Finally, clinical evidence from Muss et al. demonstrates that patients who overexpress HER2/neu are more likely to benefit from high doses of DOX (45). Due to the conflicting evidence suggesting that HER2/neu might not be involved in drug resistance, studies designed to further define the role of HER2/neu in tumor response to chemotherapeutic agents are in demand.

This work examines the correlation between the expression of HER2/neu and breast tumor cell response to DOX in a panel of eight breast cancer cell lines and finds that, in seven of the eight cell lines, there is a positive correlation of HER2/neu expression to DOX resistance.

\section{MATERIALS AND METHODS}

\section{Cell Culture}

Breast cancer cell lines (ATCC) (HS-578, BT-474, MDA-MB-453, MDA-MB-231, MDA-MB-175, MCF7, ZR-75-1, T47D) were grown in RPMI 1640 (Gibco; Burlington, ON) complete medium containing penicillin streptomycin $(2.5 \mathrm{~mL} / 500 \mathrm{~mL}$ RPMI), Lglutamine $(5 \mathrm{~mL} / 500 \mathrm{~mL}$ RPMI) and fetal bovine serum (FBS) (10\%) (Gibco). Incubation of cell lines was at $37^{\circ} \mathrm{C}$ in a $5 \% \mathrm{CO}_{2}$ atmosphere. The growth medium was changed biweekly and plates approaching $100 \%$ confluence were split into new plates by trypsinization.

\section{Determination of the Sensitivity of the Breast Cell Lines to Doxorubicin}

Exponentially growing cell monolayers were incubated with serially diluted concentrations of DOX (Sigma, Oakville, ON) $(0.1 \mathrm{nM}$ to $800 \mathrm{nM}$ in RPMI complete medium), and incubated for five days in 96-well plates. Cytotoxicity was evaluated by the sulforhodamine B assay. Briefly, the cells were fixed by the addition of $50 \mu \mathrm{l}$ of cold trichloroacetic acid (TCA) $(50 \%)$ at $4{ }^{\circ} \mathrm{C}$ for one hour. The wells were washed four times with water and stained with sulforhodamine B 


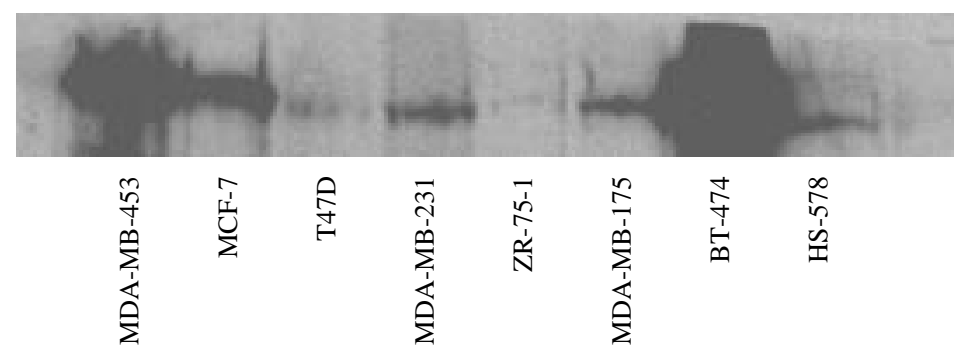

Figure 1. HER2/neu expression in breast cancer cell lines from Western blotting.

$(0.4 \%)$ (Sigma) dissolved in $1 \%$ acetic acid. The plates were air-dried and the resulting colored residue dissolved in $200 \mu \mathrm{l}$ of Tris base $(10 \mathrm{mM})$. The optical density (OD) of each well was measured at 540nM with a microplate reader (Model 3550, BioRad; Mississauga, $\mathrm{ON})$. The results were calculated from at least two independent experiments run in triplicate. Additionally, the $\mathrm{IC}_{50}$ value was calculated from each independent experiment. The graphs, therefore, represent the average $\mathrm{IC}_{50}$ for the indicated cell line.

\section{Determination of HER2/neu Levels in the Breast Tumor Cell Lines}

Exponentially growing cells were collected in cold PBS and centrifuged to separate a pellet that was then washed with hypotonic buffer. Cells were lysed by sonication ( $3 \times 10$ seconds) and the pellet (nuclei) separated from the supernatant (cytosol) by centrifugation (14 $000 \mathrm{rpm})$. The supernatant was removed and the pellet was resuspended in hypotonic buffer containing $0.1 \%$ SDS which was kept on ice for 10 minutes. The protein concentrations of each cell line were measured against a prepared standard curve based on the absorbances of nine serial dilutions at $595 \mathrm{nM}$, using the method of Bradford (46).

Sodium dodecyl sulfate polyacrylamide gel electrophoresis (SDS-PAGE) was performed as outlined (47). The samples were subjected to 8\% SDS-PAGE gels, and finally transferred to nitrocellulose membranes. The membranes were rinsed in Tris buffered saline (TBS) and Tween 20 (T) and blocked to prevent antibody binding to non-specific sites with a solution of TBS+T $+1 \%$ bovine serum albumin. To detect HER2/neu, the primary antibody (Cedar Lane; Hornby, ON) (mouse anti-human) was incubated with membranes overnight at $4^{\circ} \mathrm{C}$ (concentration 1:5000). To detect HER2/neu labeled proteins, an anti-mouse antibody (Cedar Lane) (concentration 1:3000) was incubated with membranes for 30 minutes at room temperature. Enhanced chemoluminescence (Amersham; Oakville, ON) was used to identify immuno-tagged proteins that were then visualized by exposure on Kodak X-OMAT AR film (Eastman Kodak Company, Rochester, NY).

\section{Correlation Between Breast Tumor Cell Sensitivity to Doxorubicin with Levels of HER2/neu}

Levels of HER $2 /$ neu previously identified by a single Western blot were quantified by Biolmage (Visage Electrophoresis Gel Analysis System; Ann Arbor, MI) densitometric scan and expressed in relative OD units. Statistical significance was assumed for $p<0.05$ using Mann-Whitney rank sum test. All statistical analyses were performed with the GraphPad Prism (San Diego, CA) software package. OD units indicate relative levels of HER2/neu.

\section{RESULTS}

\section{Quantification of HER2/neu}

The relative levels of HER2/neu in the eight cell lines were quantified by Western blotting (Figure 1, Table 1). BT-474 and MDA-MB-453 expressed similar amounts of the protein. The levels of HER2/neu expressed in these two cell lines were approximately 2 -fold greater than in MDA-MB-175, 1.7-fold greater in MCF-7, 5-fold greater than in both HS-578 and MDA-231, 10 -fold greater than T47D, and 26.7-fold greater than ZR-75-1. This indicates that the levels of HER2/neu was quite variable within the cell population, a distribution pattern that is critical for the validity of the correlation.

\section{Chemosensitivity}

The $\mathrm{IC}_{50}$ for DOX was determined in each of the eight tumor cell lines (Table 1, Figure 2A and 2B). The

Table 1. Doxorubicin $\mathrm{IC}_{50}$ and HER2/neu levels for breast cancer cell lines.

\begin{tabular}{lcc}
\hline \hline Breast Cancer Cell Lines & $\begin{array}{c}\text { IC }_{\mathbf{5 0}} \text { DOX } \\
(\mathbf{n M})\end{array}$ & $\begin{array}{c}\text { HER2/neu Level } \\
(\mathbf{O D})\end{array}$ \\
\hline T47D & 2.706 & 0.154 \\
MDA-MB-231 & 3.560 & 0.357 \\
MCF-7 & 4.160 & 0.978 \\
HS-578 & 6.508 & 0.351 \\
ZR-75-1 & 6.690 & 0.059 \\
MDA-MB-453 & 22.340 & 1.661 \\
BT-474 & 64.600 & 1.691 \\
MDA-MB-175 & 121.100 & 0.850 \\
\hline \hline
\end{tabular}

IC $_{\mathbf{5 0}}$ : Inhibitory concentration; OD: Optical density 

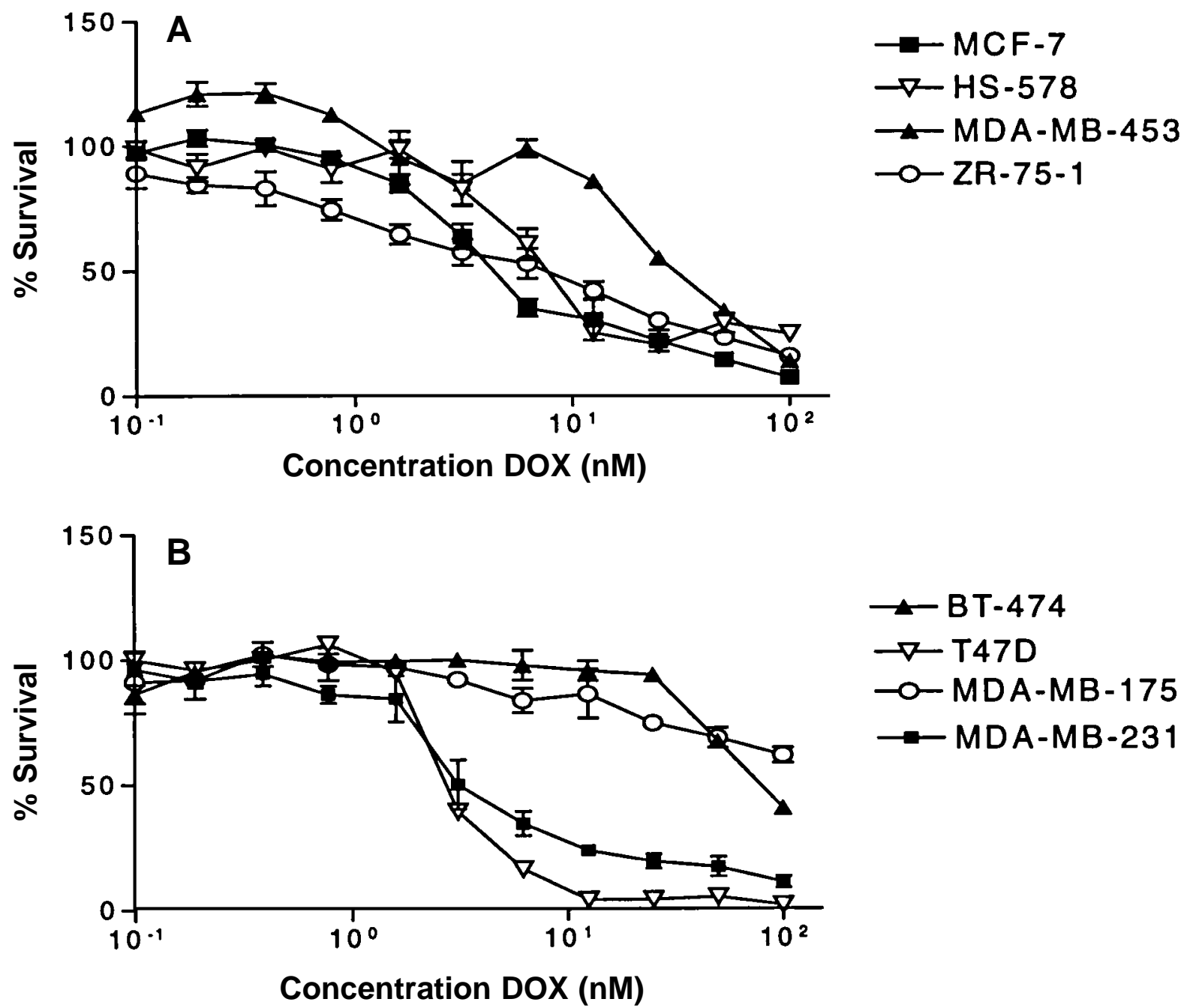

Figure 2A and 2B. Dose response curves for human breast cancer cell lines exposed to doxorubucin. Error bars show standard deviation.

most sensitive cell line to DOX observed was T47D $\left(\mathrm{IC}_{50}=2.706 \mathrm{nM}\right)$ and the least chemosensitive cell line to DOX was MDA-MB-175 $\left(\mathrm{IC}_{50}=121.1 \mathrm{nM}\right)$. The $\mathrm{IC}_{50}$ for each of the other cell lines (MDA-MB-231, MCF-7, HS-578, ZR-75-1, MDA-MB-453, BT-474) was in the range of $3.56 \mathrm{nM}$ to $64.6 \mathrm{nM}$.

\section{Correlation Analysis}

The DOX $\mathrm{IC}_{50}$ obtained for each of the cell lines was correlated with HER2/neu levels. When all eight possible points were displayed (Figure 3A) no significant correlation was observed $(p=0.08$, $\left.\mathrm{r}^{2}=0.42\right)$. The data point for MDA-MB-175 significantly deviated from linearity. Such a deviation may be due to additional mechanisms of resistance (please refer to discussion). Without this point (Figure 3B), a more linear correlation was observed between DOX chemosensitivity and HER2/neu levels $\left(p=0.022, \mathrm{r}^{2}=0.680\right)$. High HER2/neu levels appeared to correlate with reduced cell sensitivity to doxorubicin.

\section{DISCUSSION}

This study was performed with eight breast tumor cell lines that presented diverse levels of expression of HER2/neu. MDA-MB-453 and BT-474 expressed the highest levels of the oncogene, while ZR-75-1 showed the lowest levels. It was demonstrated that DOX resistance may be positively related to the expression of the HER2/neu oncogene. Although the number of different cell lines used in this correlation was relatively low, a linear dependence of sensitivity to DOX on HER2/neu levels was apparent in seven cell lines. This, along with previous basic and clinical studies, form a strong basis of evidence suggesting that HER2/neu expression is linked to chemoresistance $(23,24,35$ $39,45,48-50)$. 

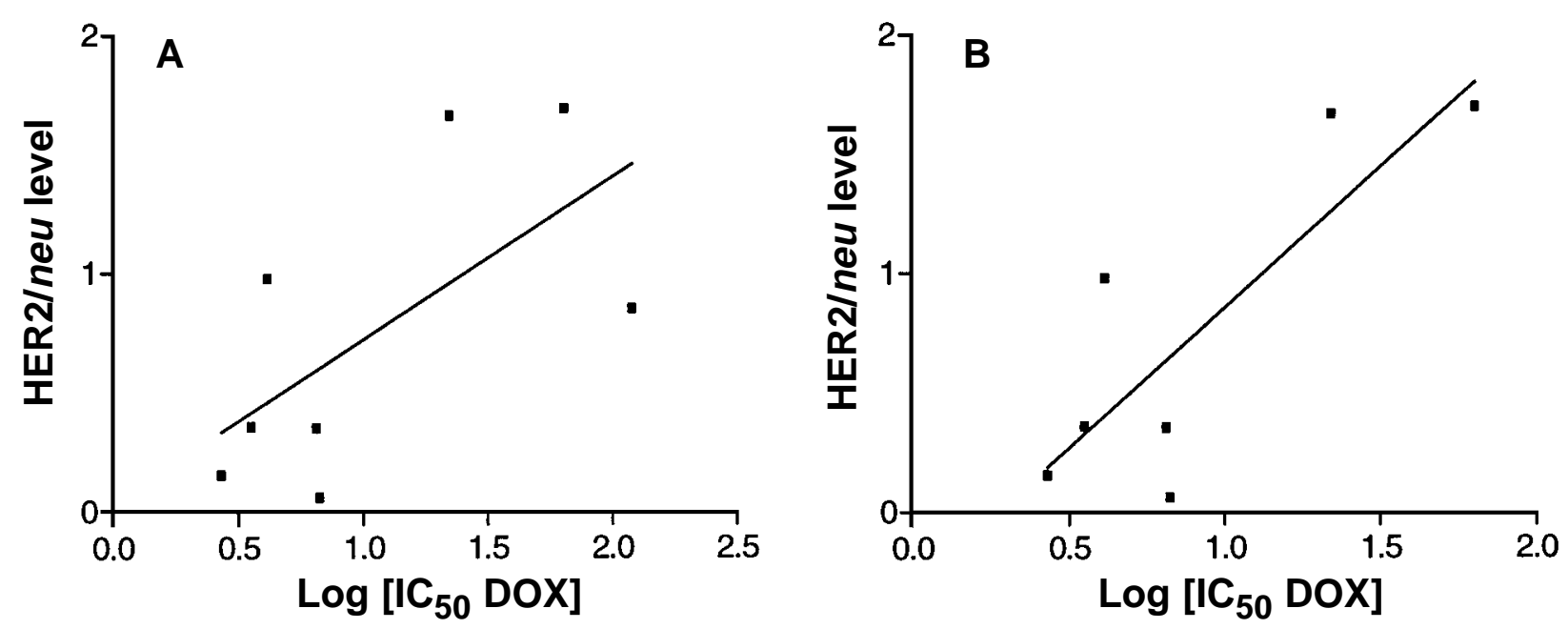

Figure 3. Correlation between HER2/neu protein levels and IC50 for doxorubicin. A: Includes a panel of eight breast cancer cell lines (HS-578, BT-474, MDA-MB-453, MDA-MB-231, MDA-MB-174, MCF-7, ZR-75-1 and T47D) $\left(p=0.08, \mathrm{r}^{2}=0.42\right)$. B: Includes a panel of seven breast cancer cell lines (as in A, not including MDA-MB-175) $\left(p=0.02, \mathrm{r}^{2}=0.68\right)$.

The exact mechanism that links overexpression of HER2/neu to DOX resistance is not clearly understood. It has been shown that altered drug accumulation or detoxification is not involved in HER2/neu mediated resistance (40). DNA repair, as well as dysregulation of cell cycle checkpoint and apoptotic mechanism seem to be responsible for the chemoresistance induced by HER2/neu overexpression, however, it remains to be determined which HER2/neu signaling cascade initiates these mechanisms (40).

In the this study, one of the cell lines, MDA-MB-175, which expressed low levels of HER2/neu, showed resistance to DOX. The value for this cell line significantly deviated from the correlation established between the seven other cell lines. The current authors believe that this cell line may express another mechanism of resistance, most probably the P-glycoprotein-mediated mechanism (mdr-1). It has been shown that HER2/neu overexpression can lead to intrinsic drug resistance independent of mdr-1 in MDAMB-435 cells (51). That is, it is possible that MDAMB-175 is a case wherein the mdr- 1 mechanism of chemoresistance dominates that of HER2/neu, and represents the central mode of resistance. The levels of P-glycoprotein (mdr-1) in MDA-MB-175 have not yet been reported. HER2/neu, however plays a prognostic role that is independent of its involvement in multi-drug resistance (mdr-1) (52).

The correlation reported in the current study establishes the value of HER2/neu levels in predicting chemosensitivity to doxorubicin. A firm correlation may then be applied in the clinic to design more effective chemotherapy regimens for solid breast tumors. The correlation may be further strengthened by extension to more cell lines. Carefully controlled experiments may begin to demonstrate whether overexpressed HER2/neu confers resistance alone or by a mechanism dependent on other factors, a finding that has applications to treatment and to patient prognosis.

\section{ACKNOWLEDGMENTS}

The authors thank the Rona and Irving Levitt Foundation for financial support.

\section{REFERENCES}

1. Slamon DJ, Godophin W, Jones LA, et al. Studies of the HER2/neu proto-oncogene in human breast and ovarian cancer. Science 244: 707-712; 1989.

2. Borg A, Tandon AK, Sigurdsson CM et al. HER-2/neu amplification predicts poor survival in node-positive breast. Cancer Research 50: 4332-4337; 1990.

3. Iglehart JD. Kraus MH. Langton BC. et al. Increased erbB-2 gene copies and expression in multiple stages of breast cancer. Cancer Research 50: 6701-6707;1990.

4. Bacus SS, Ruby SG, Weinberg DS, et al. HER-2/neu oncogene expression and proliferation in breast cancers. American Journal of Pathology 137: 103-111.1990

5. Berns EMJJ, Klijn JGM, van Staveren IL, et al. Prevalence of amplification of the oncogenes c-myc, HER2/neu and int-2 in one thousand human breast tumors: correlation with steroid receptors. European Journal of Cancer 28: 697-700; 1994.

6. Niskanen E, Blomqvist C, Franssila K, et al. Predictive value of c-erbB2, p53, cathepsin-D and histology of the primary tumour in metastatic breast cancer. British Journal of Cancer 76: 917922; 1997.

7. Yokota J, Yamamoto T, Toyoshima K, et al. Amplification of cerbB-2 oncogene in human adenocarcinomas in vivo. Lancet 1 : 765-767; 1986.

8. Kameda T, Yasui W, Yoshida K, et al. Expression of ERBB2 in human gastric carcinomas: relationship between p1852ERBB2 expression and gene amplification. Cancer Research 50: 8002$8009 ; 1990$. 
9. Suzuki S, Uno S, Fukuda Y. Cytotoxicity of anti-c-erb-2 immunoliposomes containing DOX on human cancer cells. British Journal of Cancer 72: 663-668; 1995.

10. Coussens L, Yang-Feng TL, Liao Y, et al. Tyrosine kinase receptor with extensive homology to EGF receptor shares chromosomal location with neu oncogene. Science 230: 11321139; 1985.

11. Yarden YA, Ullrich A. Growth Factor Receptor Tyrosine Kinases. Annual Reviews of Biochemistry 57: 443-78; 1988.

12. Hynes EN, Stern FD. The biology of erbB-2/neu/NHER-2 and its role in cancer. Biochimica et Biophysica Acta 1198: 165-184; 1994.

13. Cooper GM. Oncogenes. Boston: Jones and Bartlett Publishers; 1995: 118-125.

14. Bargmann CI, Hung MC and Weinberg RA. Multiple independent activations on the neu oncogene by a point mutation altering the transmembrane domain of p185. Cell 45: 649-657; 1986.

15. Di Fiore PP, Pierce JH, Kraus $\mathrm{MH}$, et al. ErbB-2 is a potent oncogene when overexpressed in NIH/3T3 cells. Science 237:178-182; 1987.

16. Roh H, Pippin J, Boswell C. Antisense oligonucleotides specific for the HER2/neu oncogene inhibit the growth of human breast carcinoma cells that overexpress HER2/neu. Journal of Surgical Research 77: 85-90; 1998.

17. Samanta A, LeVea CM, Dougall WC, Qian X, Greene MI. Ligand p185c-neu density govern receptor interactions and tyrosine kinase activation. Proceedings of the.National Academy of Science (USA). 91:1711-1715; 1994.

18. Yazici H, Muslumanoglu M, Guzey D, Yasasever V, Ozbek U, Dalay N. Amplification in tumors and benign tissue of breast cancer patients. Cancer Letters 107: 235-9; 1996.

19. Brandt B, Vogt U Schlotter CM, et al. Prognostic relevance of abberations in the erbB oncogenes froim breast, breast, ovarian, oral and lung cancers: double differential polymerase chain reaction (ddPCR) for clinical diagnosis. Gene 159: 35-42; 1995.

20. Yu D, Liu B, Tan M, Li J, Wang S, Hung M. Overexpression of c-erbB-2/neи in breast cancer cells confers increased resistance to Taxol via mdr-1 independent mechanisms. Oncogene 13: 1359-65; 1996.

21. Bitran JD, Samuels B, Trujillo $\mathrm{Y}$, et al. HER2/neu overexpression is associated with treatment failure in women with high-risk stage II and stage IIIA breast cancer (>10 involved lymph nodes) treated with high-dose chemotherapy and autologous hematopoietic progenitor cell support following standard-dose adjuvant chemotherapy. Clinical Cancer Research 2:1509-1513; 1996.

22. Zhang L, Hung MC. Sensitization of HER-2/neu-overexpressing non-small cell lung cancer cells to chemotherapeutic drugs by tyrosine kinase inhibitor emodin. Oncogene 12: 571576 .

23. Jones SE ed. Current Concepts in the Use of Doxorubicin Chemotherapy. Italy: Farmitalia CarloErba S.P.A.;1982.

24. Pratt WB, Ruddon RW, Ensminger WD, Maybaum J. The Anticancer Drugs 2nd Edition. New York:Oxford University Press; 1994.

25. Lui LF. DNA topoisomerase poisons as antineoplastic drugs. Annual Review of Biochemistry 58:351-375; 1989.

26. Corbett $\mathrm{AH}$, Osheroff $\mathrm{N}$. When good enzymes go bad: conversion of topoisomerase II to a cellular toxin by antineoplastic drugs. Chemical Research and Toxocology 6:585597; 1993.

27. Patel S, Sprung AU, Keller BA et al. Identification of yeast DNA topoisomerase II mutants resistant to the antitumor drug doxorubicin: implications for the mechanism of doxorubicin action and cytotoxicity. Molecular Pharmacology 52: 658-666;
1997.

28. Kuriyama M, Tsutsui K, Tsutsui $\mathrm{K}$ et al. Induction of resistance to etoposide and adriamycin in a human glioma cell line treated with antisense oligonucleotide complementary to the messenger ribonucleic acid of deoxyribonucleic acid topoisomerase II alpha. Neurologia Medico-Chirurgica. 37:655-661; 1997.

29. Wang H, Jiang ZG, Wong YW et al. Decreased CP-1 activity results in transcriptional down-regulation of topoisomerase Iialpha in a doxorobucin-resistant variant of human multpiple RPMI 8226. Biochemical and Biophysical Research Comunications. 237:217-224; 1997.

30. Casazza AM. Preclinical selection of new anthracyclines. Cancer Treatment Reports 70:43-49; 1986.

31. Doroshow JH. Prevention of doxorubicin-induced killing of MCF-7 human breast cancer cells by oxygen radical scavengers and iron chelating agents. Biochemistry and Biophysics Research Communications 13: 330-5; 1986.

32. Sinha BK, Katki AG, Batista G, Cowan KH, Myers CE.Differential formation of hydroxyl radicals by adriamycin in sensitive and resistant MCF-7 human breast tumor cells: implications for the mechanism of action. Biochemistry 26: 3776-81; 1987.

33. Safa AR, Glover CJ, Meyers MB, Biedler JL, Felsted RL. Vinblastine photoaffinity labeling of a high molecular weight surface membrane glycoprotein specific for multidrug resistant cells. Journal of Biological Chemistry 261: 6137; 1986.

34. Cornwell MM, Safa AR, Felsted RL, Gottesman MM, Pastan.I. Membrane vesicles form multidrug-resistant cancer cells contain a specific $150-170 \mathrm{kDa}$ protein detected by photoaffinity labeling. Proceedings of the National Academy of Science(USA) 83: 3847;1986.

35. Baselga J, Norton L, Albanell J et al. Recombinant humanized anti-HER2 antibody (Herceptin) enhances the antitumor activity of paclitaxel and doxorubicin against HER2/ney overexpressing human breast cancer xenografts. Cancer Research 58:28252831; 1998.

36. Pegram MD, Lipton A, Hayes DF et al. Phase II study of receptor-enhanced chemosensitivity using recombinant humanized anti-p185 (HER2/neu) monoclonal antibody plus cisplatin in patients with HER2/neu-overexpressing metastatic breast cancer refractory to chemotherapy treatment. Journal of Clinical Oncology 16: 2659-2671; 1998.

37. Wu L, Wu A, Jiang K. Effect of antisense c-erbB2 on biologic behaviour and chemotherapeutic drug sensitivity in human ovarian cancer cells. Chinese Journal of Obstetrics and Gynecology 31:169-172; 1996.

38. Yu D, Lui B, Tan M et al. Overexpression of c-erbB-2/neu in breast cancer cells confers increased resistance to Taxol via mdr1-independent mechanism. Oncogene 13: 1359-1365; 1996.

39. Tsai CM, Chang KT, Wu LH et al. Correlations between intrinsic chemoresistance and HER-2/neu gene expression, p53 gene mutations, and cell proliferation characteristics in nonsmall cell ling cancer cell lines. Cancer Research 56: 206-209; 1996.

40. Alaoui-Jamali MA, Paterson J, Al Moustafa AE, Yen L. The role of ErbB-2 tyrosine kinase receptor in cellular intrinsic chemoresistance: mechanisms and implications. Biochemistry and Cell Biology 75: 315-25; 1997.

41. Yen L, Nie ZR, You XL, Richard S, Langton-Webster BC, Alaoui-Jamali MA. Regulation of cellular response to cisplatin induced DNA damage and DNA repair in cells overexpressing p185(erbB-2) is dependent on the ras signaling pathway. Oncogene 14: 1827-35; 1997.

42. Pegram MD, Finn RS, Arzoo K et al. The effect of HER-2/neu overexpression on chemotherapeutic drug sensitivity in human breast and ovarian cancer cells. Oncogene 15: 537-547; 1997. 
43. Harris LN, Tang L, Tang C et al. Induction of sensitivity to doxorubicin and etoposide by transfection of MCF-7 breast cancer cells with heregulin beta-2. Clinical Cancer Research 4:1005-1012; 1998.

44. Sleijfer S, Asschert JG, Timmer-Bosscha $\mathrm{H}$ et al. Enhanced sensitivity to tumor necrosis factor-aplha in doxorubicinresistant tumor cell lines due to down-regulated c-erbB-2. International Journal of Cancer 77:101-106; 1998.

45. Muss HB, Thor AD, Berry DA et al. C-erbB-2 expression and response to adjuvant therapy in women with node-positive early breast cancer. New England Journal of Medicine 330: 12601266; 1994.

46. Bradford MM. A rapid and sensitive method for the quantification of microgram quantities of protein utilizing the principle of protein-dye binding. Analytical Biochemistry 72 : 248-254; 1976.

47. Laemmli UK. Cleavage of structural proteins during the assembly of the head of bacteriophage T4. Nature 227: 680-5; 1970 .
48. Alldred DC,Clark GM, Tandon AK, et al. HER-2/neu in node negative breast cancer: Prognostic Significance of overexpression influenced by the presence of in situ carcinoma. Journal of Clinical Oncology 10: 599-605; 1992.

49. Gusterson BA, Gelber RD. Prognostic Importance of c-erbB-2 expression in Breast Cancer. Journal of Clinical Oncology 10: 1049-1056; 1992.

50. Carlomagno C, Perrone F, Gallo C, et al. c-erb B2 overexpression decreases the benefit of adjuvant tamoxifen in early-stage breast cancer without axillary lymph node metastases. Journal of Clinical Oncology 14: 2702-8; 1996.

51. Kane SE, Gottesman MM. Multidrug Resistance in the laboratory and Clinic. Cold Spring Harbour: Cold Spring Harbour Laboratory Press; 1989.

52. Schneider J, Romero H. Correlations of P-glycoprotein overexpression and cellular prognostic factors in formalin-fixed, paraffin-embedded tumor samples from breast cancer patients. Anticancer Research 15:1117-21; 1995

Anne Elizabeth Mullin is currently in her third year of study towards a B.Sc. in Microbiology and Immunolgy at McGill University (Montreal, Quebec, Canada). After winning a McGill Summer Research Bursary Position, she conducted her research on HER2/neu oncogene under the supervision of Drs. Bertrand Jean-Claude and Brian Leyland-Jones, in the Department of Oncology (McGill University). For this research, she was awarded Merck, Sharp and Dohme award in Therapeutics by the Faculty Scholarships Committee. 